\begin{tabular}{|c|l|}
\hline Title & Vibration analysis during grass harvesting according to ISO vibration standards \\
\hline Author(s) & Kang, Tae Hwan; Kaizu, Yutaka \\
\hline Citation & $\begin{array}{l}\text { Computers and Electronics in Agriculture, 79(2), 226-235 } \\
\text { https://doi.org/10.1016/.compag.2011.10.003 }\end{array}$ \\
\hline Issue Date & 2011-11 \\
\hline Doc URL & http://hdl.handle.net/2115/48178 \\
\hline Type & article (author version) \\
\hline File Information & CEA 79-2_226-235.pdf \\
\hline
\end{tabular}

Instructions for use 


\title{
Vibration Analysis during Grass Harvesting According to ISO Vibration Standards
}

\author{
Tae-Hwan Kang ${ }^{\text {a }}$, Yutaka Kaizu ${ }^{\text {b,* }}$
}

${ }^{a}$ Department of Biosystems Engineering, College of Agriculture, Life and Environment Science, Chungbuk National University,

12 Gaesindong, Heungdukgu, Cheongju, Chungbuk 361-763, Korea

b,* Graduate School of Agriculture, Hokkaido University, Kita 9, Nishi 9, Kita Ku, Sapporo 060-8589, Japan; Corresponding author’s email: kaizu@bpe.agr.hokudai.ac.jp

\section{Abstract}

3 This research evaluated the working efficiency and comfort of operation by measuring vibration acceleration of tractors during grass harvesting. A real-time kinematic global positioning system and an inertial measurement unit installed in a tractor normally used by farmers during grass harvesting were used to acquire tractor vibration acceleration data. Analysis of the position and vibration acceleration data of tractors by a Fourier transformation yielded a power spectrum of vibration acceleration at each frequency $(1-10 \mathrm{~Hz})$ and position. The root mean square of vibration acceleration at each frequency $(1-10 \mathrm{~Hz})$ was calculated with the center frequency of the $1 / 3$ octave bands $(1.0,1.25,1.6,2.0,2.5,3.15,4,5,6.3,8$, and $10 \mathrm{~Hz}$ ) based on ISO standards. To evaluate the working efficiency in the grassland, geographical information system maps were generated using the power spectrum of vibration 
1 acceleration and the limit on working time for each frequency that negatively affected the

2 tractor driver. The vibration acceleration in the longitudinal $\left(a_{x}\right)$ and lateral $\left(a_{y}\right)$ directions at

3 the center frequency of the $1 / 3$ octave band below $2.0 \mathrm{~Hz}$ exceeded the fatigue-decreased

4 proficiency and reduced the comfort boundaries stipulated in ISO 2631 (1974). In the area

5 where working characteristics are severe, the vibration acceleration in the vertical direction

$6\left(a_{z}\right)$ is high. The vibration acceleration in the $a_{z}$ direction at the center frequency of the $1 / 3$

7 octave band $(5-10 \mathrm{~Hz})$ clearly indicates discomfort during grass harvesting and a decrease in

8 the work efficiency beyond one hour. The total vibration acceleration $\left(a_{v}\right)$ at the center

9 frequency of $5.0 \mathrm{~Hz}$ of the $1 / 3$ octave band served to evaluate comfort in the whole field

10 during grass harvesting - the $a_{v}$ value is higher than that at other frequencies. The area with

11 severe working characteristics showed a higher $a_{v}$ value at the center frequency of $8.0 \mathrm{~Hz}$

12 than that at other frequencies.

13

Keywords: RTK-GPS, IMU, ISO standard, Fourier transformation, 1/3 octave band center

frequency, vibration acceleration

\section{Introduction}

There are three effects of vibration on the human body: psychological, physiological, and work efficiency. The physiological effect has the most direct impact on people. In 1976, Japan enacted regulations on vibrations based on ISO/DIS 2631 (1974). Those regulations covered basic issues such as using the vibration level to indicate standard values, and the use of 
1 measured values in the vertical direction of the vibration level, following JIS C 1510 (1995)

2 as the measurement standard.

With significant development of a wide range of machines due to industrialization,

4 noise-related regulations have broadened in range and detail. For example, ISO 2631-1(1997)

5 and ISO/DIS 8041(2003) revised the standards for full human body vibration and hand-arm

6 vibrations. In the Japanese industry standards, JIS 7760-1(2004) and 7760-2(2004), which are

7 the basic requirements for measurement, the method and evaluation of full-body vibrations

8 were revised in 2004 based on ISO/DIS 8041(2003) and ISO 2631(1997). The vibration

9 regulations for agricultural machines, ISO 5008(1979), specify the method to measure the

10 operator's full-body vibration for agricultural tractors and field machines. Using these

11 standards, many studies have reported the effects of vibrations of agricultural tractors on

12 human health and the comfort of many kinds and sizes of tractors with different tires and

13 transmissions and offered methods for estimating tractor vibration (Kennes et al., 1999;

$14 \quad$ Servadio et al., 2007)

15 Sam and Kathirval (2006) reported that the four primary harmful effects of vibration are 16 degraded health, impaired activities, impaired comfort, and motion sickness. Kumar et al. 17 (2001) investigated the strength of tractor vibrations and their effects on humans, such as back 18 injuries or waist pain. They used standards based on ISO 2631(1985) and ISO 5008 (1979). Pope and Hansson (1992) reported that tractors generate vibrations with a frequency of 1-7 $\mathrm{Hz}$, which are harmful to the human body, and generate those as high as $4-8 \mathrm{~Hz}$, which can 21 cause waist pain or spinal injuries.

In this study, we acquired vibration and position information during actual grass harvesting 
measurement unit (IMU). We used a Fourier transform to convert the strength of vibration, by frequency and location, to work information and generated a geographical information system (GIS) map for the frequency range 1-10 Hz, which negatively affects humans during tractor work. We analyzed this GIS map to determine the locations where the vibration intensity in the $1-10 \mathrm{~Hz}$ frequency range exceeded ISO standards, thereby affecting work. We discussed a new method of evaluating work comfort. This study analyzed vibrations based on ISO 2631(1974), ISO 5008(1979), JIS B 7761-1, 2(2004), and JIS F 0907(2003).

\section{Materials and methods}

\subsection{Experimental setup}

The field experiment was performed at Hamanaka, Hokkaido grassland in 2007. The total area of the grassland is 3.6 ha, but the GIS map covered only an area of 2.4 ha, where the vibration during grass harvesting was actually measured using a Kubota MD $107(78 \mathrm{~kW})$ tractor. During grass harvesting, a mower conditioner with a mowing width of $3 \mathrm{~m}$ was attached to the tractor and vibration data was collected while driving at a work speed of $3.0 \mathrm{~m}$ $\mathrm{s}^{-1}$. This speed was the normal practical speed for this operation. The working speed was almost constant. The data sets recorded during turning were omitted and only those of straight paths were used for analysis. We interviewed the operator to determine the regions where he felt it was difficult to work. We will refer to the combination of factors, including the risk of the tractor rolling over on the operator, an increase in the drag of the mower conditioner, and unstable work postures of an operator during harvesting, as workability. Fig. 1 shows the MD 107 harvesting grass at the Hamanaka grassland and Table 1 shows the tractor's main 
specifications.

An RTK-GPS (MS750, Trimble Navigation Ltd., Sunnyvale, CA) and an IMU (Japan Aviation Electronics Industry Ltd., Tokyo, Japan) installed in a tractor normally used by farmers during actual grass harvesting measured the positions and vibrations. A virtual reference station (VRS)/RTK-GPS receiver with 2-cm precision acquired the position data at a data frequency of $20 \mathrm{~Hz}$. The acceleration in the $a_{x}, a_{y}$, and $a_{z}$ directions was measured by the IMU with a frequency of $25 \mathrm{~Hz}$. The acceleration data in the three directions was corrected by subtracting gravity. These data were stored in a laptop through an RS-232C interface. Fig. 2 shows the locations of the installed sensors. For studying vibration acceleration, the location of the vibration acceleration sensor is most important. ISO 8041(2003) and JIS B 7760-1(2004) stipulate that the sensor should be installed in the same plane as the seat surface for measurement. In this study, however, installing the vibration acceleration sensor on the seat interfered with the operator during harvesting; thus, it was installed on the side of the operator's seat to perform measurements without obstructing the work.

Fig. 3 illustrates the tractor's working trajectory, measured by the RTK-GPS during grass harvesting at Hamanaka. The area enclosed by the red triangle indicates poor workability.

\subsection{Preprocessing of tractor vibration acceleration data}

As shown in Fig. 3, the length of one working path is about $200 \mathrm{~m}$. Windowing the complete vibration acceleration data in a single path, as shown in Fig. 4, associated the position with spectral information. After performing a discrete Fourier transform, the center of 
1 the window serves as the representative position. In this study, we used 256 samples within

2 the window at a sampling frequency of $25 \mathrm{~Hz}$. Because the vibration acceleration data was

3 acquired at a work speed of $3 \mathrm{~m} \mathrm{~s}^{-1}$ and $25 \mathrm{~Hz}$, the sampling distance corresponds to a special distance of about $0.12 \mathrm{~m}$. Thus, the frequency and intensity measurements of vibration acceleration in the test space are accurate to within $0.12 \mathrm{~m}$. The 256 samples used for the Fourier transform correspond to the data acquired during $10.24 \mathrm{~s}$ and include the vibration acceleration data for a distance of about $30 \mathrm{~m}$. A Hanning window function, used as in Eq. (1), diminished the effect of the sampling data on both ends. Fig. 4 shows the application of a Hanning window function on a specified number of vibration acceleration data samples acquired from straight-line work and the sampling data interval.

$$
h(n)=\left\{\begin{array}{l}
\sqrt{\frac{2}{3}}\left(1-\cos \left(\frac{2 \pi n}{N-1}\right)\right. \\
0
\end{array} \quad(0 \leq n \leq N-1)\right.
$$

\subsection{Transformation of vibration acceleration data to multidimensional spatial data}

This study analyzed the vibration acceleration power spectrum using a discrete Fourier transform based on the power spectral density function of JIS F 0907(2003) specifications as in Eqs. (2) and (3).

$$
\begin{aligned}
& f_{i}=i \Delta f=\frac{i}{T_{s}} \\
& S_{a}\left(f_{i}\right)=(\Delta f) \cdot \frac{1}{N}\left|\sum_{l=1}^{n} x_{l} e^{-2 \pi j j_{i} l}\right|^{2},
\end{aligned}
$$

where $f_{i}$ is the $i$ th frequency, $\Delta f$ is the bandwidth representing the frequency resolution, and $T_{s}$ is the time duration for the Fourier transform. This study used 256 data samples for a discrete Fourier transform at a frequency of $25 \mathrm{~Hz}$; thus, $T_{s}$ was $10.24 \mathrm{~s}$ and $\Delta f$ was $0.09766 \mathrm{~Hz} . N$ is the number of vibration acceleration data samples. The root mean square 
1 (r.m.s.) of the vibration accelerations is calculated as

$2 \quad a_{i}=\sqrt{S_{a}\left(f_{i}\right)}$

ISO 2631(1974) defines the vibration acceleration intensity level of fatigue as the

4 deterioration of work efficiency according to the vibration acceleration in the $a_{x}, a_{y}$, and

$5 \quad a_{z}$ directions at a center frequency of the 1/3 octave band. This study calculated the weighted

$6 \mathrm{rms}$ of the vibration acceleration in the longitudinal $\left(a_{x w r m s}\right)$, lateral $\left(a_{y w r m s}\right)$, and vertical

7 directions ( $a_{\text {zwrms }}$ ) using Eqs. (5), (6), and (7), respectively, and compared the values with ISO

$8 \quad 2631(1974)$.

9

$$
a_{x w r m s}=k_{x}\left[\sum_{i}\left(W_{a i} a_{x_{i}}\right)^{2}\right]^{\frac{1}{2}}
$$

$$
a_{Y w r m s}=k_{y}\left[\sum_{i}\left(W_{a i} a_{y_{i}}\right)^{2}\right]^{\frac{1}{2}}
$$

$$
a_{\text {Zwrms }}=k_{z}\left[\sum_{i}\left(W_{a i} a_{z_{i}}\right)^{2}\right]^{\frac{1}{2}}
$$

Here $k_{x}, k_{y}$, and $k_{z}$ are coefficients that depend on measurement methods for the longitudinal $(x)$, lateral $(y)$, and vertical directions $(z)$, respectively. $W_{a i}$ is the vibration acceleration coefficient at the $1 / 3$ octave band with the center frequency $f=10^{i / 10} \mathrm{~Hz} . a_{x_{i}}$, $a_{y_{i}}$, and $a_{z_{i}}$ are the $i$ th r.m.s. acceleration in the three directions. In this study, because the IMU is installed on the floor of the tractor, $k_{x}, k_{y}$, and $k_{z}$ were $0.25,0.25$, and 0.4 , respectively. With these weighting coefficients, the acceleration on the seat can be estimated 18 from the acceleration on the floor (ISO 2631-1, 1997). In addition, $W_{a i}$ calculates the vibration acceleration coefficient defined in ISO 5008(1979) at each selected frequency. The 
1 synthesized vibration acceleration was calculated using Eq. (8). This is composed of the

2 longitudinal, lateral, and vertical components obtained using Eqs. (5), (6), and (7), respectively, to examine the level of comfort during grass harvesting (JIS F 0907, 2003).

$$
a_{v}=\sqrt{a_{x w r m s}^{2}+a_{y w r m s}^{2}+a_{z w r m s}^{2}}
$$

The position and acceleration were measured simultaneously during grass harvesting. Because the position data recorded with the GPS included time data, analysis of the vibration acceleration and position data using this method enables us to determine the intensity spectrum of the vibration acceleration at any time, as shown in Fig. 5. We used this method over the whole grassland area to investigate the spatial characteristics of machine vibration during grass harvesting.

\section{Results and discussion}

3.1 Characteristics of vibration acceleration in the longitudinal $\left(a_{x}\right)$ and lateral $\left(a_{y}\right)$ directions

Fig. 6 illustrates the deterioration of work efficiency due to fatigue and the vibration strength level of comfort along the three axes with the $1 / 3$ octave band specified in ISO 2631(1974) as the center frequency. As shown in Fig. 6, the vibration strength level of fatigue and deterioration of work efficiency is low in the $a_{x}$ and $a_{y}$ directions in the range $1-2 \mathrm{~Hz}$; that in the $a_{z}$ direction is low in the range $4-10 \mathrm{~Hz}$. The lowest frequency on each axis negatively affects fatigue, work efficiency, or comfort.

In this study, therefore, we discuss the characteristics of tractor vibration during grass harvesting at $1 / 3$ octave band center frequencies from 1.0 to $10 \mathrm{~Hz}$ in the $a_{x}, a_{y}$, and $a_{z}$.The vibration strength level at which fatigue work efficiency deteriorates was mapped for 
1 each frequency in the range $1.0-10 \mathrm{~Hz}$ for the whole field. After analyzing the vibration

2 characteristics during grass harvesting, we diagnosed the machine workability on the 3 grassland.

4 Fig. 7 compares the average vibration acceleration in the $a_{x}$ direction. The level of 5 vibration strength work efficiency decreases in the $1 / 3$ octave band center frequency range $1.0-10 \mathrm{~Hz}$ for the whole field and areas with poor workability. The gray and white points are the averaged vibration acceleration values in the $a_{x}$ direction for the entire field and the area pointed out by the operator having poor workability, respectively. As shown in Fig. 7, the

9 average of vibration acceleration for the whole field reached $3.033 \mathrm{~m} \mathrm{~s}^{-2}$ at $1.0 \mathrm{~Hz}$. Calculating the work time from the average value of the vibration acceleration of the whole field, we get $25 \mathrm{~min}$ below $2.0 \mathrm{~Hz}$, where work fatigue increases and work efficiency decreases. Even in the crucial areas identified by the operator, the vibration acceleration is highest at $1.0 \mathrm{~Hz}$, and the work time, based on fatigue work efficiency at $1.0 \mathrm{~Hz}, 1.25 \mathrm{~Hz}$, and 2.0 Hz decreases below 6 min. Table 2 shows the statistics of vibration acceleration in the $a_{x}$ direction for the whole field and poor workability areas for the center frequency.

Fig. 8 shows the GIS map of the maximum vibration acceleration in the $a_{x}$ direction for the center frequency range $1.0-10 \mathrm{~Hz}$. Over the whole field, the maximum vibration acceleration in the $a_{x}$ direction exceeded $1.0 \mathrm{~m} \mathrm{~s}^{-2}$, and for specific areas, it exceeded $4.0 \mathrm{~m}$ $\mathrm{s}^{-2}$. Within poor workability areas, many areas exhibit maximum vibration acceleration in excess of $5 \mathrm{~m} \mathrm{~s}^{-2}$. Fig. 9 shows the GIS map of the entire field for each 1/3 octave band center frequency and illustrates the maximum vibration acceleration. The center frequency of the $1 / 3$ octave band that showed maximum acceleration in the $a_{x}$ direction is below $2.0 \mathrm{~Hz}$. Note that the maximum vibration acceleration at $1.0 \mathrm{~Hz}$ covers $80 \%$ of the entire field. Even in 
1 poor workability areas, the maximum vibration acceleration at the center frequency of $1.0 \mathrm{~Hz}$ exceeds $90 \%$.

Fig. 10 shows the GIS map created by calculating the maximum vibration acceleration for the entire field in the $a_{x}$ direction (as shown in Fig. 8) from the vibration strength level for the deterioration of work efficiency from fatigue, as specified in ISO 2631(1974). The work time limit for the maximum vibration acceleration in the $a_{x}$ direction is mainly distributed below $1 \mathrm{~min}$ for the whole field owing to the $1 / 3$ octave band center frequency of $1.0 \mathrm{~Hz}$, as shown in Fig. 9. These results show that, in this experiment, the vibration acceleration in the direction of movement caused operator fatigue or deterioration of work efficiency at work times below 1 min owing to a center frequency of $1.0 \mathrm{~Hz}$.

Fig. 11 compares the average vibration acceleration in the $a_{y}$ direction and the vibration strength level of work efficiency for the whole field and poor workability areas. The gray points are the average values of vibration acceleration for the whole field; the white points are the averages of vibration acceleration in the $a_{y}$ direction. The average vibration acceleration for the field reached a maximum of $2.478 \mathrm{~m} \mathrm{~s}^{-2}$ at $1.0 \mathrm{~Hz}$; below the $1 / 3$ octave band vibration center frequency of $2.0 \mathrm{~Hz}$, the vibration acceleration exceeded $1.150 \mathrm{~m} \mathrm{~s}^{-2}$-higher than that above $2.0 \mathrm{~Hz}$. In the area of poor workability, the vibration acceleration was also higher at $1.0 \mathrm{~Hz}$ and $2.0 \mathrm{~Hz}$ than at the other frequencies. Calculating the work time limit based on the average vibration acceleration yielded a work time below 25 min for the whole field at a center frequency below $2.0 \mathrm{~Hz}$; in areas of poor workability, work times below 1 $\min$ at $1.0 \mathrm{~Hz}$ and $2.0 \mathrm{~Hz}$ resulted in fatigue or deterioration of work efficiency. Table 3 shows the statistical values for vibration acceleration in the $a_{y}$ direction for the whole field and areas of poor workability at each 1/3 octave band center frequency. 
Fig. 12 shows the GIS map of the maximum vibration acceleration in the $a_{y}$ direction for

2 the $1 / 3$ octave band center frequencies $1.0-10 \mathrm{~Hz}$. The maximum vibration in the $a_{y}$

3 direction for the whole field was mainly distributed in areas over $1.0 \mathrm{~m} \mathrm{~s}^{-2}$. In the white line

4 triangle area within the poor workability area, the maximum vibration acceleration exceeds

$5 \quad 1.4 \mathrm{~m} \mathrm{~s}^{-2}$ throughout, while areas over $2.2 \mathrm{~m} \mathrm{~s}^{-2}$ also exist. Fig. 13 shows the GIS map of 1/3

6 octave band center frequencies of $1.0-10 \mathrm{~Hz}$, showing the maximum vibration acceleration

7 for each area of the field. As shown in Fig. 13, the 1/3 octave band center frequency showing

8 the maximum vibration acceleration exceeds $90 \%$ of the whole field area at frequencies below

$9 \quad 1.6 \mathrm{~Hz}$. Areas of poor workability showed tendencies similar to those of the whole field. Fig.

1014 shows the GIS map of the calculated work time limit that causes fatigue or deterioration of

11 work efficiency using the maximum vibration acceleration in the $a_{y}$ direction, according to

12 ISO 2631(1974). The work time limit for the maximum vibration acceleration in the $a_{y}$

13 direction is mainly distributed below $1 \mathrm{~min}$ for the whole field owing to the effect of the $1 / 3$

14 octave band center frequencies below $2.0 \mathrm{~Hz}$; similar results were observed in areas of poor

15 workability.

\section{$17 \quad 3.2$ Characteristics of vibration acceleration in the vertical direction $\left(a_{z}\right)$}

Fig. 15 compares the average vibration acceleration in the $a_{z}$ direction and the vibration

19 strength level of fatigue work efficiency for the whole field and poor workability areas for the $1 / 3$ octave band center frequencies in the range $1.0-10 \mathrm{~Hz}$. The gray points are the average values of vibration acceleration for the whole field calculated for each center frequency. The white points are the average values of the vibration acceleration in the $a_{z}$ direction in areas 
1 of poor workability. As shown in Fig. 15, the average vibration acceleration showed high

2 values $0.909 \mathrm{~ms}^{-2}$ and $0.985 \mathrm{~ms}^{-2}$ at $1.0 \mathrm{~Hz}$ and $2.0 \mathrm{~Hz}$, respectively. In addition, the average

3 of vibration acceleration at center frequencies $5.0-10 \mathrm{~Hz}$ with low deterioration of work

4 efficiency was above $0.7 \mathrm{~m} \mathrm{~s}^{-2}$.

At the $1 / 3$ octave band center frequency range $5.0-10 \mathrm{~Hz}$, workability decreases to $1 \mathrm{~h}$. In areas of poor workability, the average vibration acceleration is the highest at $1.0 \mathrm{~Hz}$ and 2.0 Hz. The work time in the range $4.0-10 \mathrm{~Hz}$ with low vibration strength of work fatigue efficiency deterioration is below $2.5 \mathrm{~h}$. Table 4 summarizes the statistical values of the vibration acceleration in the $a_{z}$ direction of the whole field and areas of poor workability for each center frequency.

Fig. 16 shows the GIS map of the maximum vibration acceleration in the $a_{z}$ direction for center frequencies $1.0-10 \mathrm{~Hz}$. The maximum vibration for the whole field in the $a_{z}$ direction was mainly distributed in areas over $0.6 \mathrm{~m} \mathrm{~s}^{-2}$. In the poor workability area, the maximum vibration acceleration exceeds $1.2 \mathrm{~m} \mathrm{~s}^{-2}$.

Fig. 17 shows the $1 / 3$ octave band center frequency map with the maximum vibration acceleration in the $a_{z}$ direction for the whole field. The center frequency of the $1 / 3$ octave band with the maximum vibration acceleration in the $a_{z}$ direction is broadly distributed from 1.0 to $10 \mathrm{~Hz}$; however, $80 \%$ of the field was at $4.0-10 \mathrm{~Hz}$. Even in the identified poor workability areas, the center frequencies were broadly distributed in the $1.0-10 \mathrm{~Hz}$ range. Fig. 18 shows a GIS map obtained by calculating the maximum vibration acceleration in the $a_{z}$

21 direction from the vibration strength level according to deterioration of work efficiency, as specified by ISO 2631(1974). In Fig. 18, the work time for the vibration acceleration in the $a_{z}$ direction at which work efficiency decreased was $1 \mathrm{~h}$ in the whole field and poor 
workability areas.

\subsection{Evaluation of comfort by composite vibration acceleration along the three axes}

We used the composite vibration acceleration along the three axes to evaluate the level of comfort, according to the specifications in JIS B 7760-1(2004) and JIS B 7760-2(2004). This was achieved by calculating the composite vibration acceleration. In this paper, the maps for the center frequencies of 5 and $8 \mathrm{~Hz}$ are shown because these two maps show the distinguished difference between normal and poor workability areas. Table 5 summarizes the comfort evaluation method according to the composite vibration acceleration specified in JIS B 7760-1(2004) and JIS B 7760-2(2004).

In Fig. 19, the composite vibration acceleration and degree of comfort at the center frequency of $5.0 \mathrm{~Hz}$ are shown as a GIS map for each whole field. Fig. 19(a) shows that composite vibration accelerations over $1.0 \mathrm{~m} \mathrm{~s}^{-2}$ are widely distributed in the whole field. In particular, the composite vibration value of the grass harvesting areas pointed out by the operator as high exceeded $2.0 \mathrm{~m} \mathrm{~s}^{-2}$, which was $1.0 \mathrm{~m} \mathrm{~s}^{-2}$ higher than that at other locations. The comfort evaluation shown in Fig. 19(b) evaluated $70 \%$ of the whole field as "uncomfortable," while it rated the poor workability areas identified by the operator as "considerably uncomfortable." Fig. 20 shows the GIS map evaluating the composite vibration acceleration and comfort at $8.0 \mathrm{~Hz}$; Fig. 20(a) shows that the area with a composite vibration acceleration of over $0.6 \mathrm{~m} \mathrm{~s}^{-2}$ is widely distributed over the field. The poor workability areas showed a high composite vibration value of $1.2 \mathrm{~m} \mathrm{~s}^{-2}$, and thus, they were evaluated as being "considerably uncomfortable." 


\section{Conclusions}

In this study, we used a system made up of an RTK-GPS and an IMU installed on a farm tractor to simultaneously acquire vibration acceleration and location information during actual grass harvesting. The vibration strength acquired through a Fourier transform was analyzed on the basis of the location information. A GIS map was created for the 1-10 Hz frequency band, which negatively influences workers using the tractor. The analysis determined whether the vibration of any frequency exceeded ISO standards, thereby affecting workability and efficiency; moreover, the machine workability on the grassland was evaluated. A Fourier transform was applied to the vibration acceleration in the $a_{x}, a_{y}$, and $a_{z}$ directions, and they were combined with location information to generate a GIS map representing the vibration strength. We compared the 3 -axis vibration acceleration for each $1 / 3$ octave band center frequency with the vibration strength levels that cause fatigue or deterioration of work efficiency according to ISO 2631(1974) and provided GIS mapping of the work time limits.

As a result, it was observed that the level of fatigue increased or the work efficiency deteriorated for work times of 6 min below $2.0 \mathrm{~Hz}$ for the vibration acceleration in the $a_{x}$ and $\left(a_{x}\right)$ directions. On the other hand, with the vibration acceleration in the $a_{z}$ direction, machine workability deteriorated significantly when the work time exceeded $1 \mathrm{~h}$ at $5.0-10 \mathrm{~Hz}$. A GIS map of work comfort was generated on the basis of the composite vibration acceleration calculated from the 3 -axis vibration acceleration for the $1 / 3$ octave band. These results demonstrate that the method of acquiring vibration acceleration data and the frequency analysis of vibration acceleration, as spatial information implemented in this study, are effective in identifying and evaluating machine workability in the whole field. 


\section{References}

2

ISO 2631, 1974(E), Guide for the evaluation of human exposure to whole-body vibration. International Organization for Standardization.

ISO 2631-1, 1997, Evaluation of human exposure to whole-body vibration-Part 1: General requirements. International Organization for Standardization.

ISO 5008, 1979(E), Agricultural wheeled tractors and field machinery - Measurement of whole-body vibration of the operator. International Organization for Standardization.

ISO/DIS 8041, 2003, Human response to vibration-Measuring instrumentation. International Organization for Standardization.

JIS B 7760-1, 2004, Whole-body vibration-Part 1: Measuring instrumentation. Japanese Industrial Standard.

JIS B 7760-2, 2004, Whole-body vibration-Part 2: General requirements for measurement and evaluation method. Japanese Industrial Standard.

JIS C 1510, 1995, Vibration level meter. Japanese Industrial Standard.

JIS F 0907, 2003, Mechanical vibration - Guidelines for the measurement, reporting and evaluation of vibration with regard to habitability passenger and merchant ships. Japanese Industrial Standard.

Kennes, P., Anthonis, J., Clijmans, L., Romon, H., 1999. Construction of a portable test rig to perform experimental modal analysis on mobile agricultural machinery. Journal of Sound and Vibration, 228 (2), 421-441

Kumar, A., Mahajan, P., Mohan, D., Varghese, M., 2001. Tractor vibration severity and driver health: a study from rural India. Journal of Agricultural Engineering Research, 80 (4), 
2 Pope, M. H., Hansson, T. H., 1992. Vibration of the spine and low back pain. Clinical Orthopedics, 279, 49-59.

Sam, B., Kathirvel, K., 2006. Vibration characteristics of walking and riding type power 5 tillers. Biosystems Engineering, 95 (4), 517-528.

6 Servadio, P., Marsili, A., Belfore, N. P., 2007. Analysis of driving seat vibrations in high forward speed tractors. Biosystems Engineering, 97 (2), 171-180.

8 
Table 1

Tractor specifications.

\begin{tabular}{ccc}
\hline & Model No. & Kubota MD 107 \\
& Driving method & 4WD \\
\hline \multirow{3}{*}{ Engine } & Model No. & Kubota F5802-L \\
& Displacement $[\mathrm{cc}]$ & 5832 \\
& Max. power $[\mathrm{kW} / \mathrm{rpm}]$ & $78 / 2400$ \\
& Max. torque $[\mathrm{kg} \cdot \mathrm{m} / \mathrm{rpm}]$ & $39.9 / 1300$ \\
\hline \multirow{4}{*}{ Dimensions } & Overall length $[\mathrm{mm}]$ & 4210 \\
& Overall width $[\mathrm{mm}]$ & 2040 \\
& Overall height $[\mathrm{mm}]$ & 2695 \\
& Wheelbase $[\mathrm{mm}]$ & 2565 \\
& Weight $[\mathrm{kg}]$ & 3860 \\
\hline \multirow{2}{*}{ Tires } & Front & $13.6-24-6 \mathrm{PR}$ \\
& Rear & $16.9-38-8 \mathrm{PR}$ \\
\hline Transmission & Speeds & F16/R16 \\
\hline
\end{tabular}


Table 2

Statistical values of vibration acceleration in the longitudinal direction $\left(a_{x}\right)$ for the whole field and poor workability areas.

\begin{tabular}{ccccccccc}
\hline $\begin{array}{c}\text { Frequency } \\
{[\mathrm{Hz}]}\end{array}$ & \multicolumn{3}{c}{ Whole field $\left[\mathrm{m} \mathrm{s}^{-2}\right]$} & \multicolumn{4}{c}{ Poor workability area $\left[\mathrm{m} \mathrm{s}^{-2}\right]$} \\
\cline { 2 - 9 } Avg. & Max. & Min. & S. E. & Avg. & Max. & Min. & S. E. \\
\hline 1.00 & 3.033 & 9.855 & 0.016 & 1.265 & 4.183 & 8.723 & 1.793 & 1.540 \\
\hline 1.25 & 1.224 & 4.785 & 0.020 & 0.616 & 1.435 & 4.673 & 0.084 & 1.099 \\
\hline 1.60 & 1.352 & 4.676 & 0.042 & 0.670 & 0.462 & 1.494 & 0.054 & 0.343 \\
\hline 2.00 & 1.210 & 3.333 & 0.060 & 0.483 & 1.352 & 2.115 & 0.717 & 0.298 \\
\hline 2.50 & 0.976 & 2.493 & 0.063 & 0.407 & 0.190 & 0.748 & 0.008 & 0.142 \\
\hline 3.15 & 0.774 & 2.780 & 0.064 & 0.278 & 0.121 & 0.801 & 0.007 & 0.141 \\
\hline 4.00 & 0.712 & 2.416 & 0.046 & 0.246 & 0.761 & 1.141 & 0.286 & 0.206 \\
\hline 5.00 & 0.574 & 2.848 & 0.062 & 0.194 & 0.640 & 0.974 & 0.252 & 0.166 \\
\hline 6.30 & 0.534 & 3.704 & 0.072 & 0.204 & 0.665 & 1.432 & 0.401 & 0.234 \\
\hline 8.00 & 0.594 & 3.826 & 0.050 & 0.215 & 0.651 & 0.991 & 0.351 & 0.118 \\
\hline 10.00 & 0.802 & 4.260 & 0.061 & 0.269 & 0.654 & 0.950 & 0.390 & 0.130 \\
\hline
\end{tabular}


Table 3

Statistical values of vibration acceleration in the lateral direction $\left(a_{y}\right)$ for the whole field and poor workability areas.

\begin{tabular}{ccccccccc}
\hline $\begin{array}{c}\text { Frequency } \\
{[\mathrm{Hz}]}\end{array}$ & \multicolumn{3}{c}{ Whole field $\left[\mathrm{m} \mathrm{s}^{-2}\right]$} & \multicolumn{4}{c}{ Poor workability area $\left[\mathrm{m} \mathrm{s}^{-2}\right]$} \\
\cline { 2 - 9 } Avg. & Max. & Min. & S. E. & Avg. & Max. & Min. & S. E. \\
\hline 1.00 & 2.478 & 7.789 & 0.024 & 1.079 & 3.105 & 5.929 & 1.560 & 0.900 \\
\hline 1.25 & 1.209 & 5.779 & 0.017 & 0.641 & 0.738 & 8.141 & 0.029 & 1.050 \\
\hline 1.60 & 1.341 & 4.699 & 0.027 & 0.636 & 0.909 & 5.072 & 0.078 & 1.051 \\
\hline 2.00 & 1.510 & 4.981 & 0.039 & 0.585 & 2.104 & 3.336 & 1.187 & 0.559 \\
\hline 2.50 & 0.775 & 4.933 & 0.031 & 0.359 & 0.456 & 2.737 & 1.524 & 0.612 \\
\hline 3.15 & 0.553 & 2.129 & 0.032 & 0.212 & 0.266 & 1.665 & 0.007 & 0.384 \\
\hline 4.00 & 0.448 & 2.104 & 0.043 & 0.184 & 0.642 & 1.402 & 0.231 & 0.298 \\
\hline 5.00 & 0.352 & 2.018 & 0.040 & 0.163 & 0.606 & 1.397 & 0.255 & 0.308 \\
\hline 6.30 & 0.409 & 3.974 & 0.049 & 0.205 & 0.650 & 1.428 & 0.323 & 0.268 \\
\hline 8.00 & 0.439 & 2.536 & 0.054 & 0.177 & 0.693 & 1.307 & 0.341 & 0.206 \\
\hline 10.00 & 0.536 & 2.725 & 0.067 & 0.178 & 0.649 & 0.887 & 0.423 & 0.113 \\
\hline
\end{tabular}


Table 4

Statistical values of vibration acceleration in the vertical direction $\left(a_{z}\right)$ for the whole field and poor workability areas for each center frequency.

\begin{tabular}{ccccccccc}
\hline $\begin{array}{c}\text { Frequency } \\
{[\mathrm{Hz}]}\end{array}$ & \multicolumn{3}{c}{ Whole field $\left[\mathrm{m} \mathrm{s}^{-2}\right]$} & \multicolumn{4}{c}{ Poor workability area $\left[\mathrm{m} \mathrm{s}^{-2}\right]$} \\
\cline { 2 - 8 } Avg. & Max. & Min. & S. E. & Avg. & Max. & Min. & S. E. \\
\hline 1.00 & 0.909 & 3.461 & 0.012 & 0.415 & 1.148 & 1.839 & 0.778 & 0.220 \\
\hline 1.25 & 0.528 & 1.821 & 0.018 & 0.275 & 0.168 & 0.862 & 0.003 & 0.136 \\
\hline 1.60 & 0.656 & 2.510 & 0.018 & 0.305 & 0.292 & 2.161 & 0.003 & 0.377 \\
\hline 2.00 & 0.985 & 3.517 & 0.042 & 0.370 & 1.338 & 2.261 & 0.517 & 0.404 \\
\hline 2.50 & 0.674 & 1.979 & 0.041 & 0.279 & 0.139 & 0.543 & 0.010 & 0.102 \\
\hline 3.15 & 0.587 & 1.841 & 0.053 & 0.198 & 0.110 & 0.608 & 0.009 & 0.144 \\
\hline 4.00 & 0.580 & 1.744 & 0.059 & 0.209 & 0.844 & 1.335 & 0.422 & 0.204 \\
\hline 5.00 & 0.823 & 2.216 & 0.094 & 0.279 & 1.060 & 1.540 & 0.546 & 0.165 \\
\hline 6.30 & 0.783 & 3.669 & 0.152 & 0.228 & 0.970 & 1.299 & 0.627 & 0.139 \\
\hline 8.00 & 0.697 & 2.249 & 0.233 & 0.185 & 0.967 & 1.371 & 0.660 & 0.116 \\
\hline 10.00 & 0.924 & 2.379 & 0.188 & 0.218 & 1.057 & 1.645 & 0.747 & 0.152 \\
\hline
\end{tabular}


Table 5

Comfort evaluation according to composite vibration acceleration.

\begin{tabular}{cc}
\hline Range of composite vibration acceleration & Comfort evaluation \\
\hline Under $0.315\left[\mathrm{~m} \mathrm{~s}^{-2}\right]$ & Not uncomfortable \\
\hline $0.315-0.65\left[\mathrm{~m} \mathrm{~s}^{-2}\right]$ & A little uncomfortable \\
\hline $0.5-1.0\left[\mathrm{~m} \mathrm{~s}^{-2}\right]$ & Somewhat uncomfortable \\
\hline $0.8-1.6\left[\mathrm{~m} \mathrm{~s}^{-2}\right]$ & Uncomfortable \\
\hline $1.25-2.5\left[\mathrm{~m} \mathrm{~s}^{-2}\right]$ & Considerably uncomfortable \\
\hline More than $2.5\left[\mathrm{~m} \mathrm{~s}^{-2}\right]$ & Extremely uncomfortable \\
\hline
\end{tabular}


Click here to download Figure: Fig.1_YUNAA-6.doc

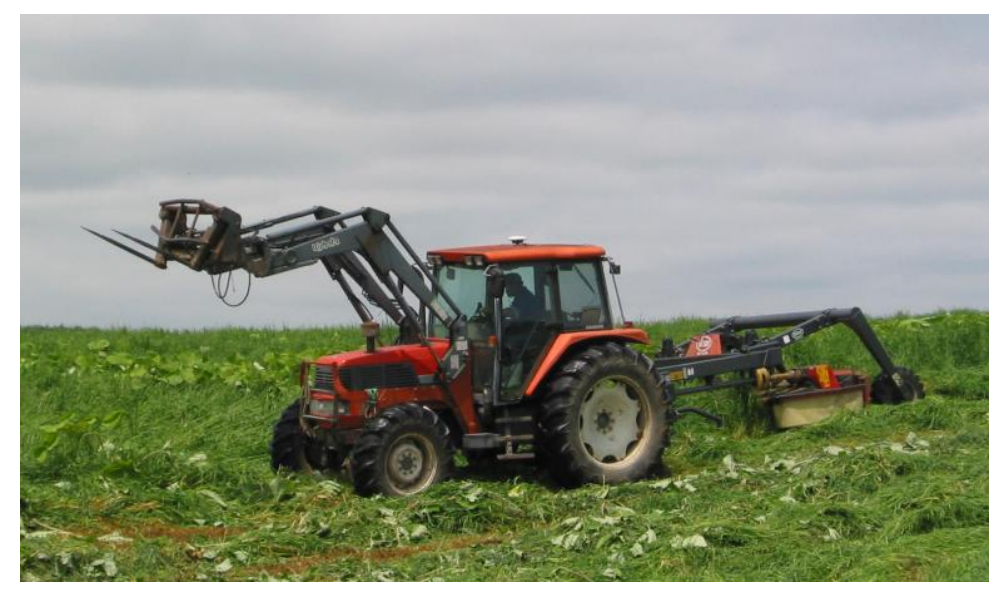

Fig. 1 Grass harvesting at Hamanaka grassland. 


\section{Figure 2}

Click here to download Figure: Fig.2_YUNAA-6.doc

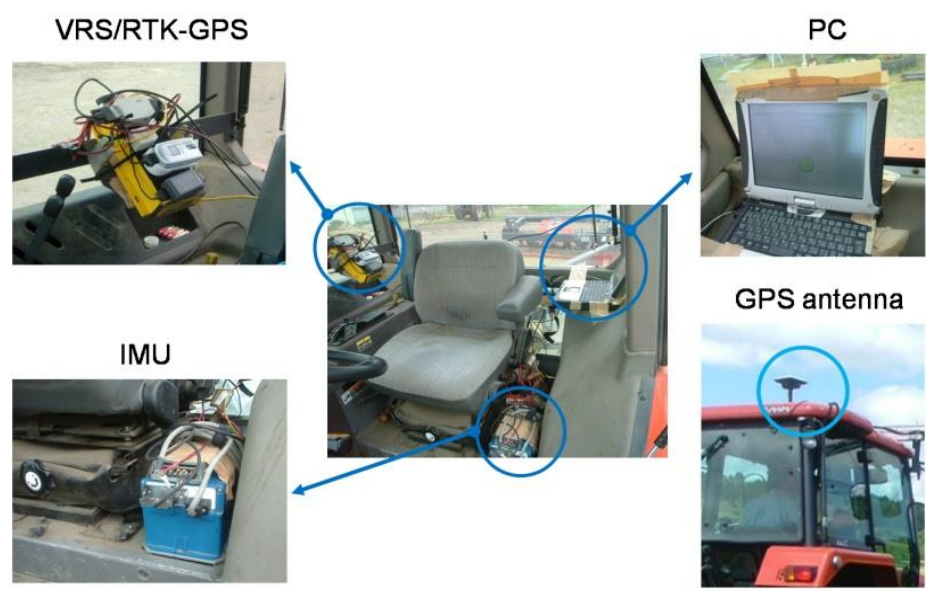

Fig. 2 Installation of the tractor vibration data-acquisition system. 
Click here to download Figure: Fig.3_YUNAA-6.doc

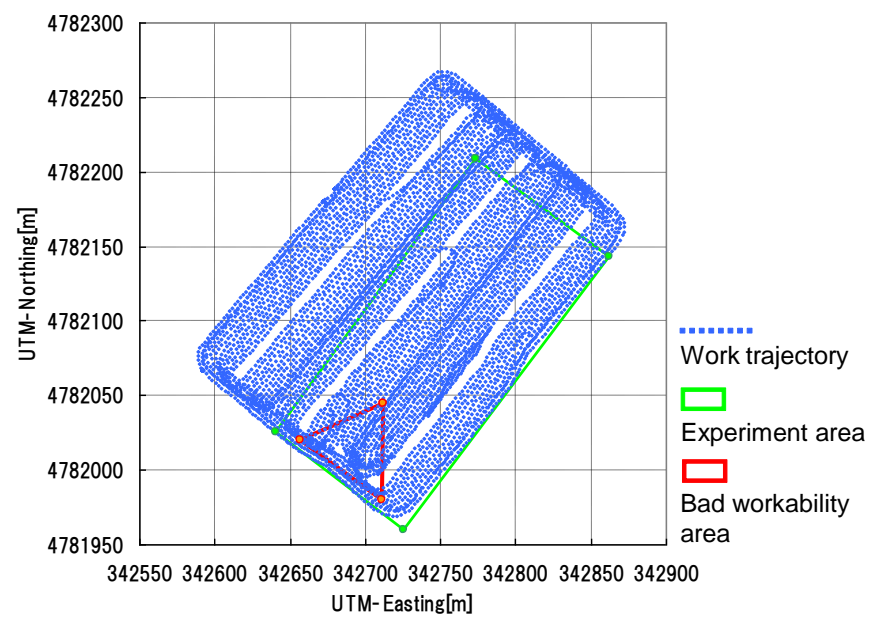

Fig. 3 Working trajectory of the tractor during grass harvesting and workability investigation locations. 

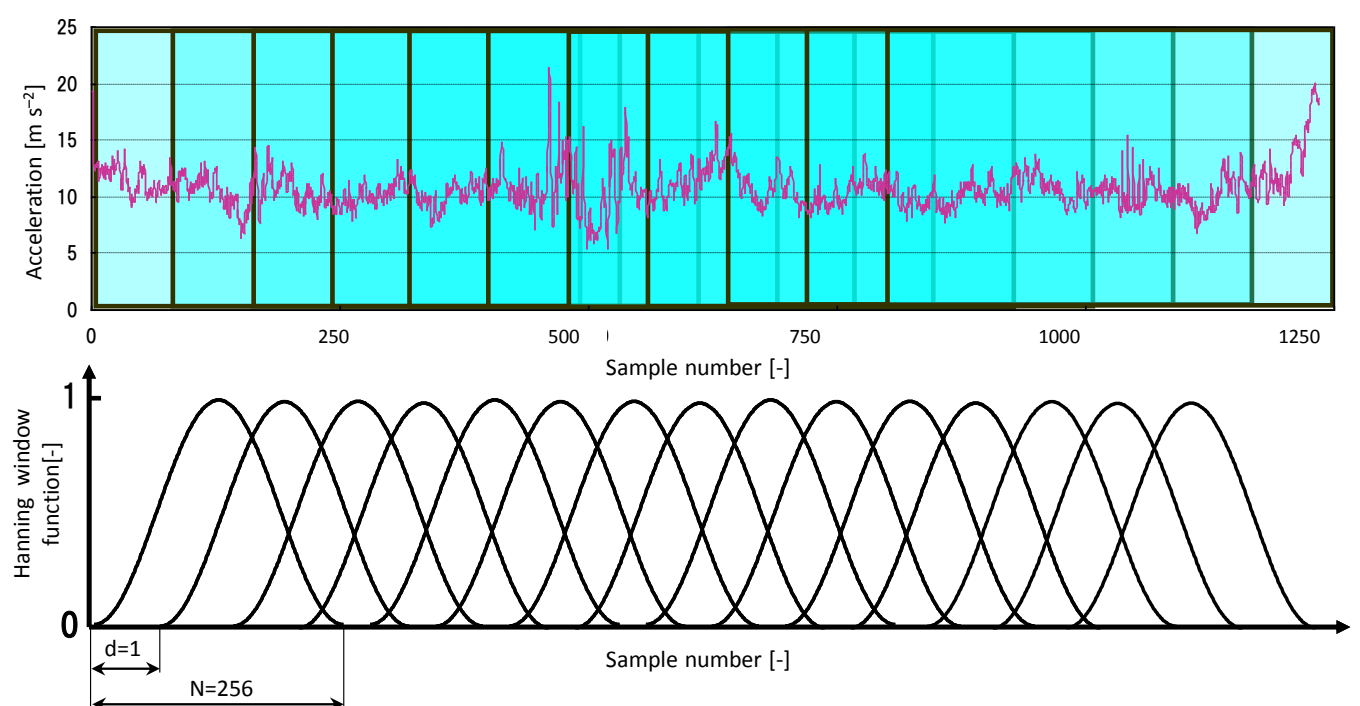

Fig. 4 Applying the Hanning window function to the sampling data 
igure 5

Click here to download Figure: Fig.5_YUNAA-6.doc

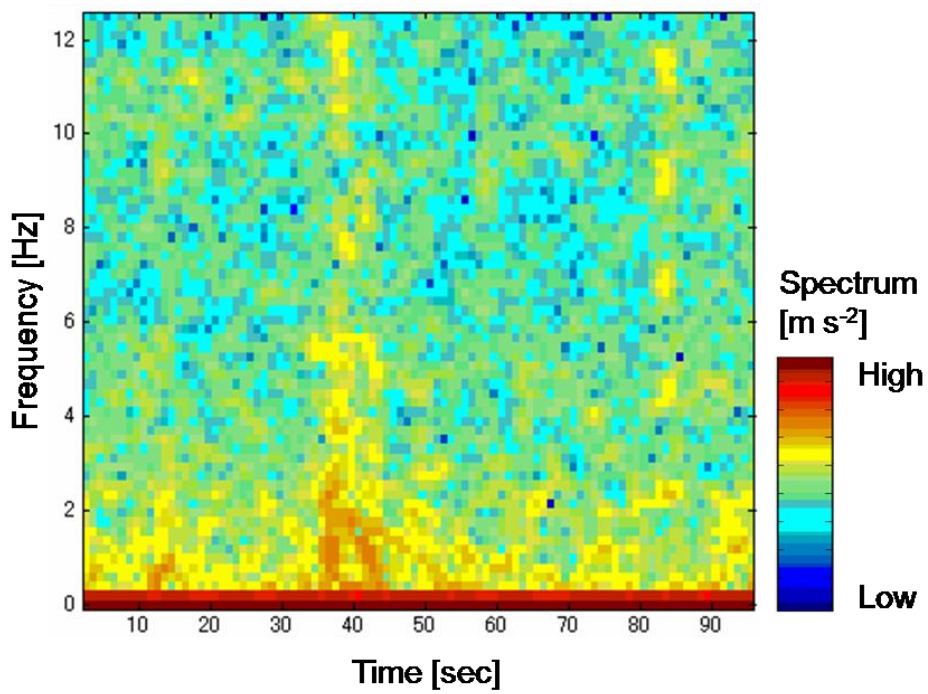

Fig. 5 Vibration strength at each frequency according to the Fourier transformation. 


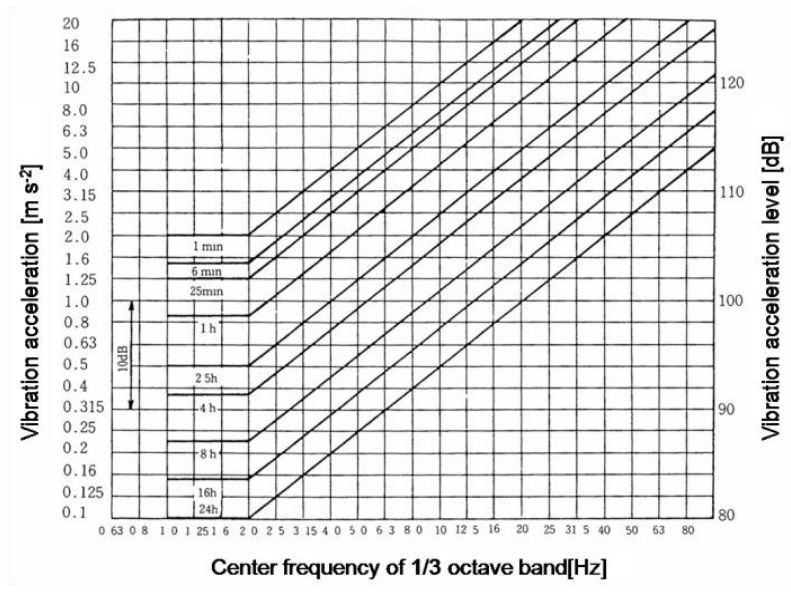

(a) Longitudinal and lateral direction.

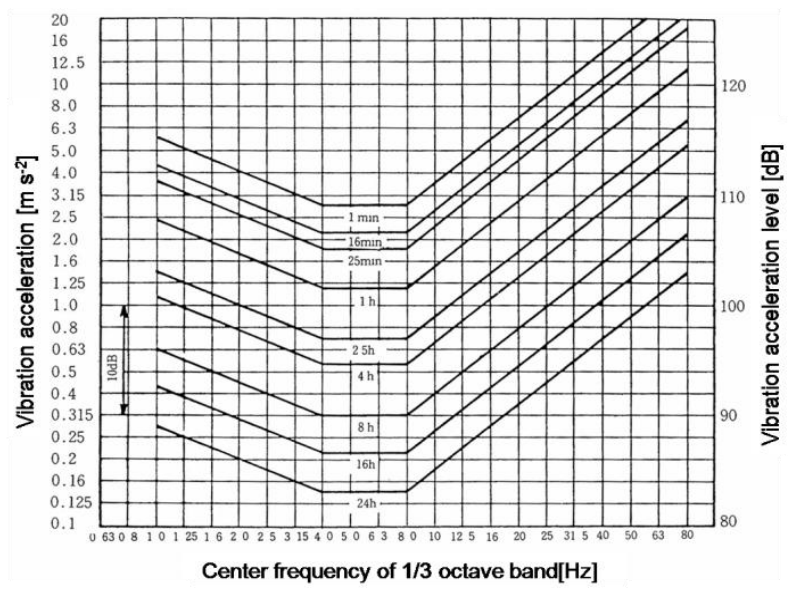

(b) Vertical direction.

Fig. 6 Vibration strength levels of fatigue work efficiency decrease along the three axes. 


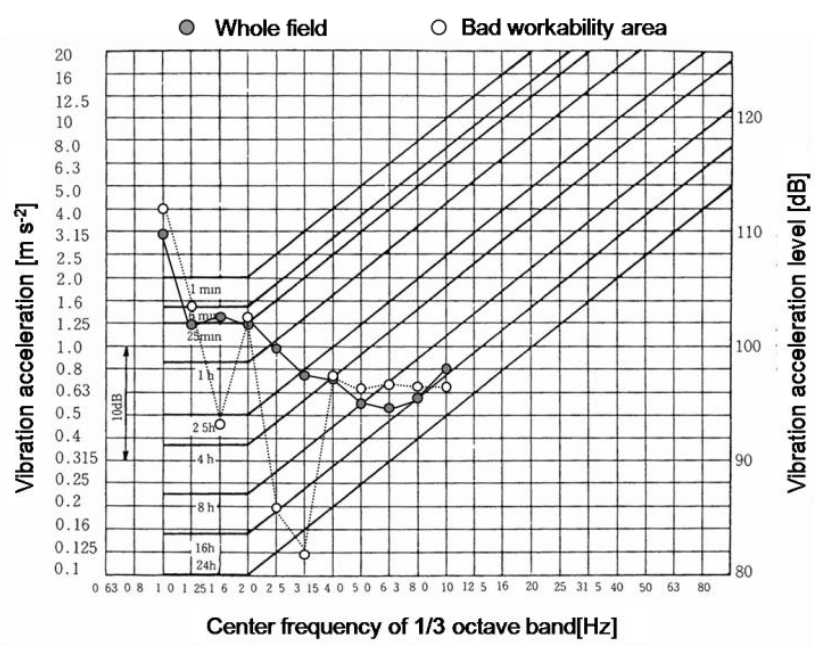

Fig. 7 Vibration strength levels of fatigue work efficiency decrease according to the vibration acceleration in the longitudinal direction $\left(a_{x}\right)$. 
Figure 8

Click here to download Figure: Fig.8_YUNAA-6.doc

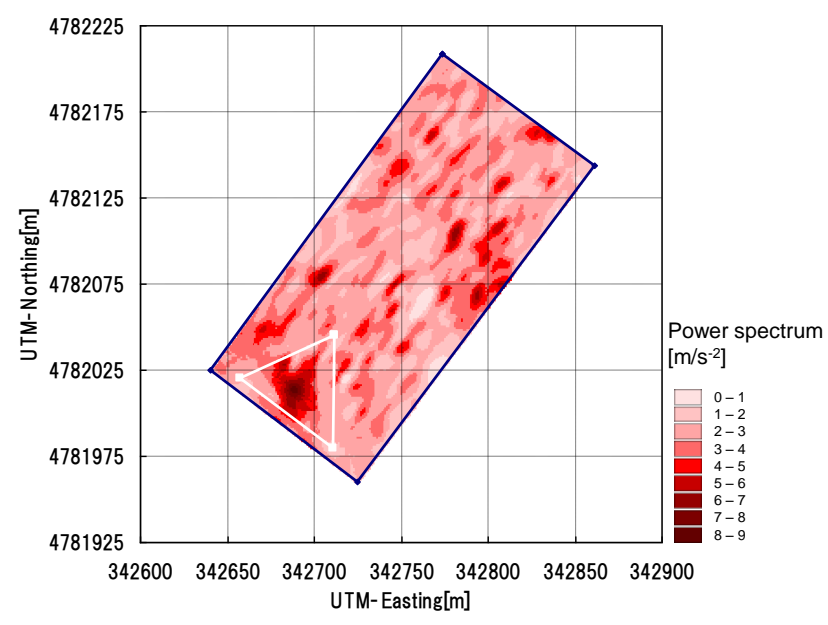

Fig. 8 GIS map of the maximum vibration acceleration in the longitudinal direction $\left(a_{x}\right)$ for 1-10 Hz. 
Click here to download Figure: Fig.9_YUNAA-6.doc

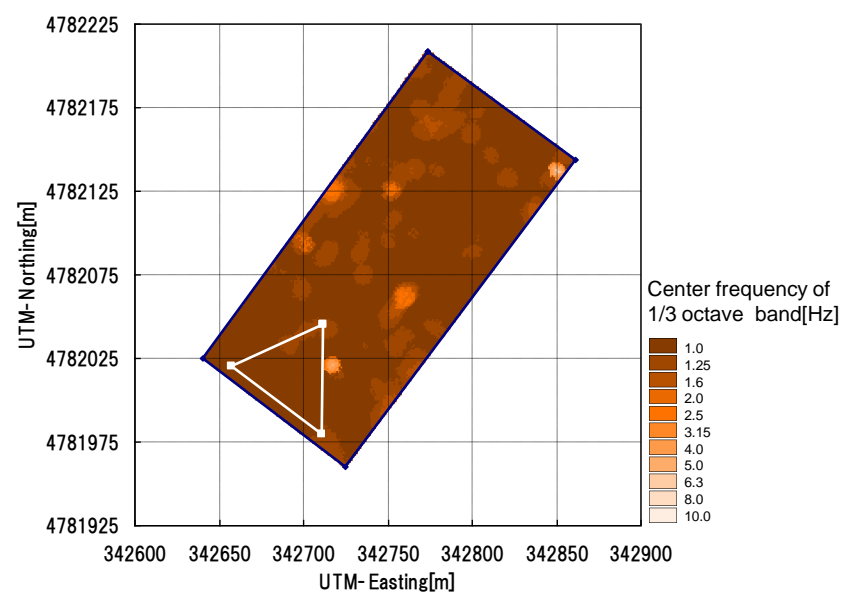

Fig. 9 GIS map of the $1 / 3$ octave band centre frequency distribution for maximum vibration acceleration in the longitudinal direction $\left(a_{x}\right)$. 


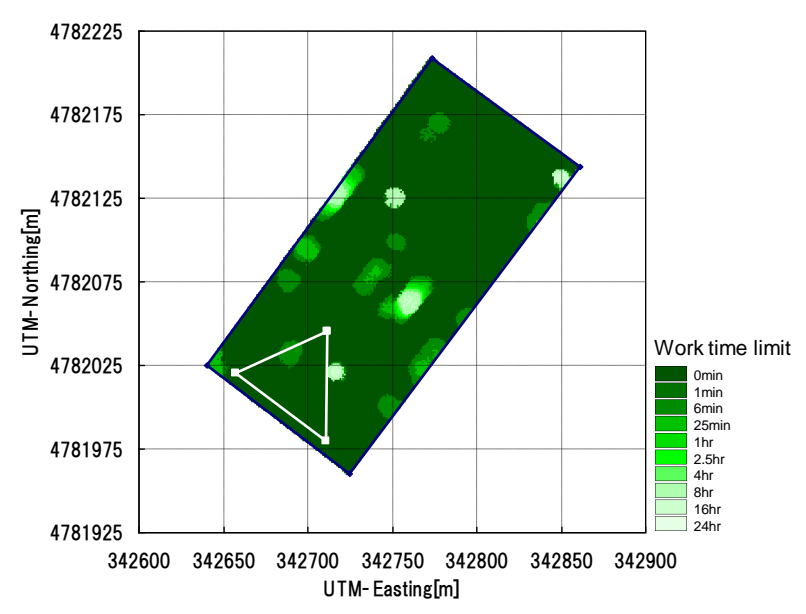

Fig. 10 GIS map of work time limit for vibration acceleration in the longitudinal direction $\left(a_{x}\right)$. 


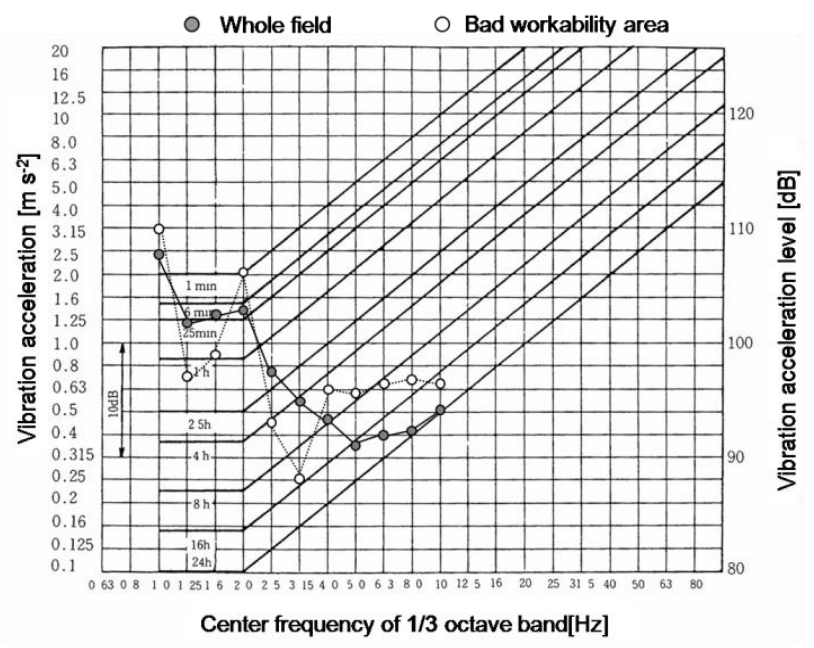

Fig. 11 Vibration strength levels of fatigue work efficiency decrease according to the vibration acceleration in the lateral direction $\left(a_{y}\right)$. 


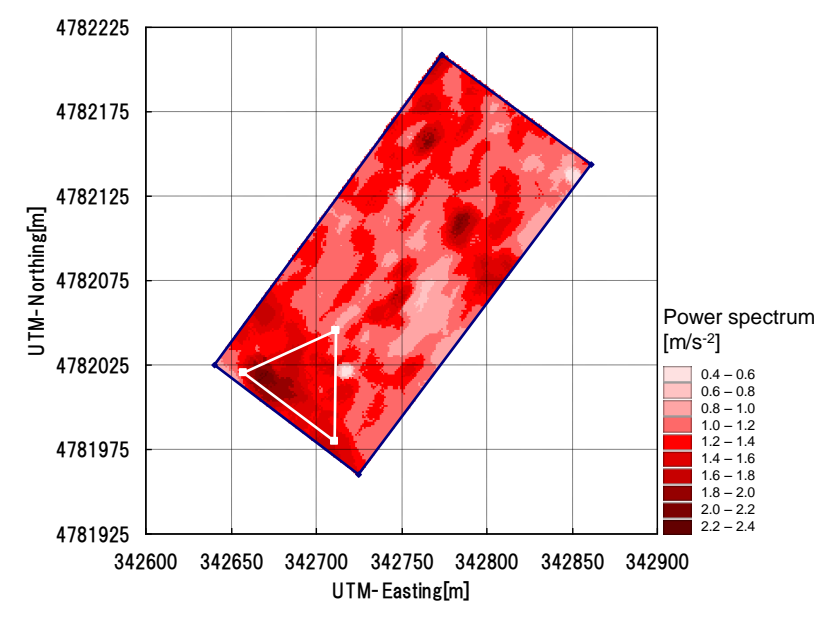

Fig. 12 GIS map of the maximum vibration acceleration in the lateral direction $\left(a_{y}\right)$ for $1-10$ Hz. 


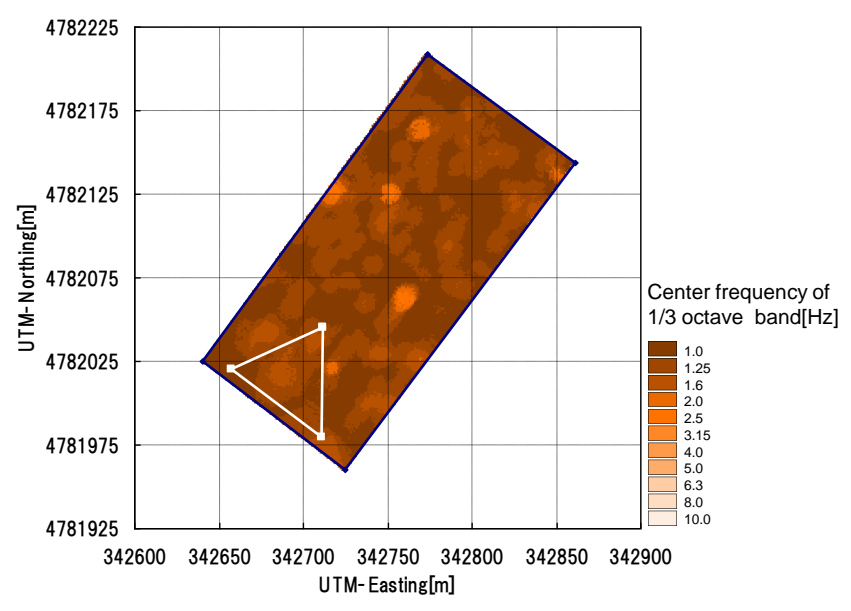

Fig. 13 GIS map of the $1 / 3$ octave band center frequency distribution for maximum vibration acceleration in the lateral direction $\left(a_{y}\right)$. 


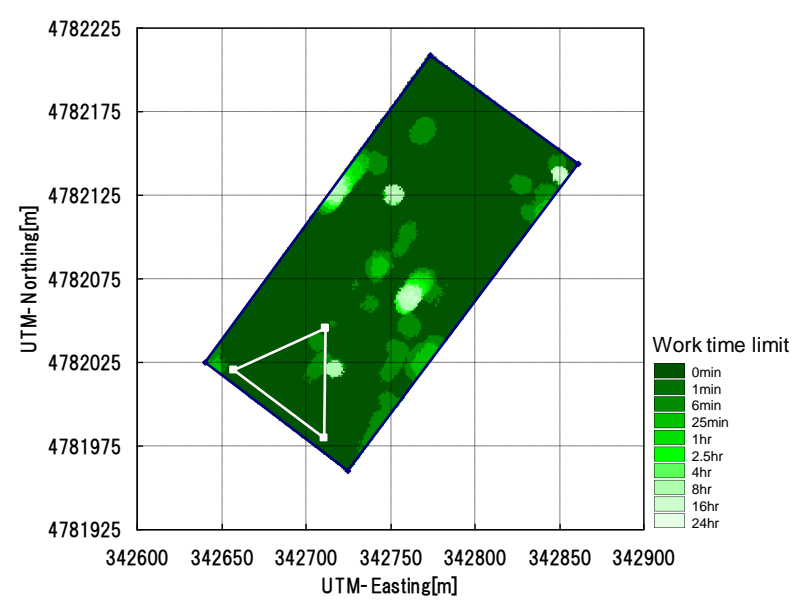

Fig. 14 GIS map of work time limit for vibration acceleration in the lateral direction $\left(a_{y}\right)$. 


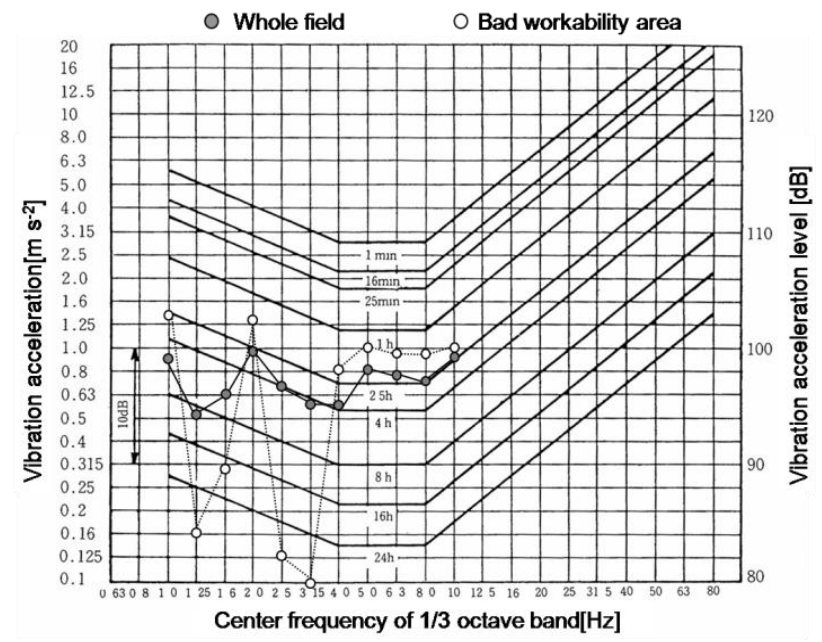

Fig. 15 Vibration strength levels of fatigue work efficiency decrease according to vibration acceleration in the vertical direction $\left(a_{z}\right)$. 


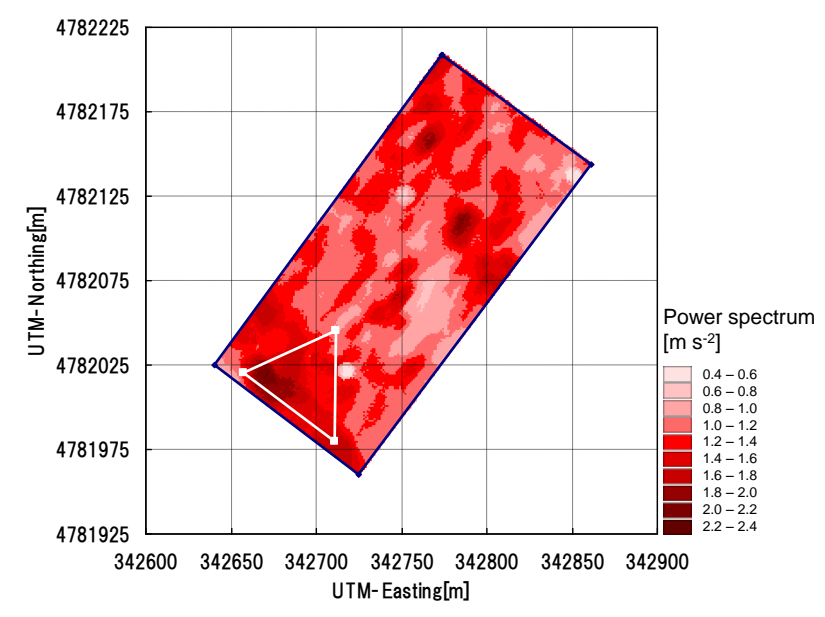

Fig. 16 GIS map of maximum vibration acceleration in the vertical direction $\left(a_{z}\right)$ for $1-10$ $\mathrm{Hz}$. 


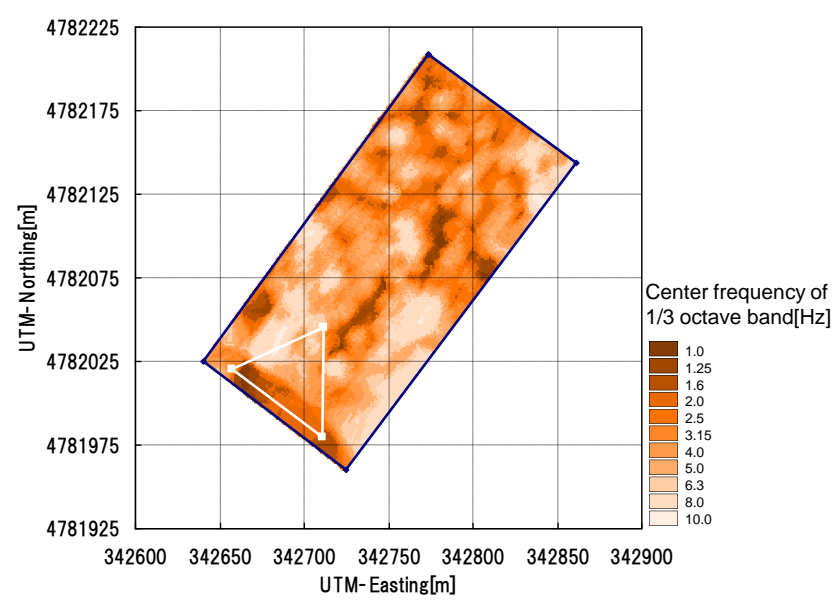

Fig. 17 GIS map of the $1 / 3$ octave band center frequency distribution for the maximum vibration acceleration in the vertical direction $\left(a_{z}\right)$. 


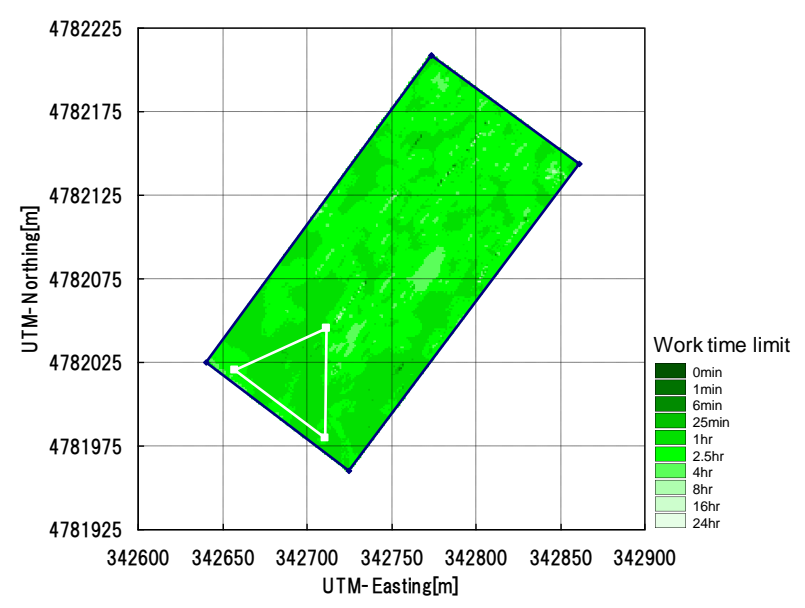

Fig. 18 GIS map of work time limit for vibration acceleration in the vertical direction $\left(a_{z}\right)$. 


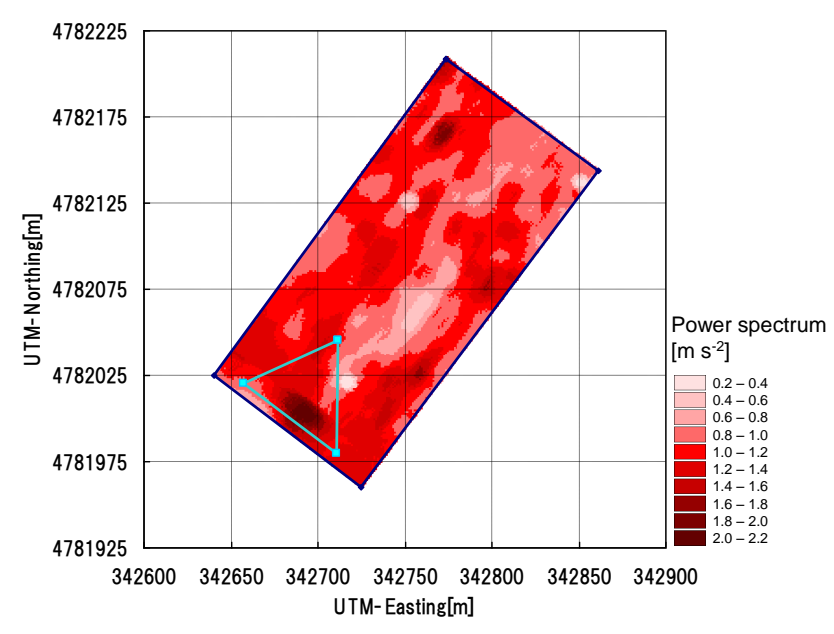

(a) Composite vibration acceleration at $5.0 \mathrm{~Hz}$

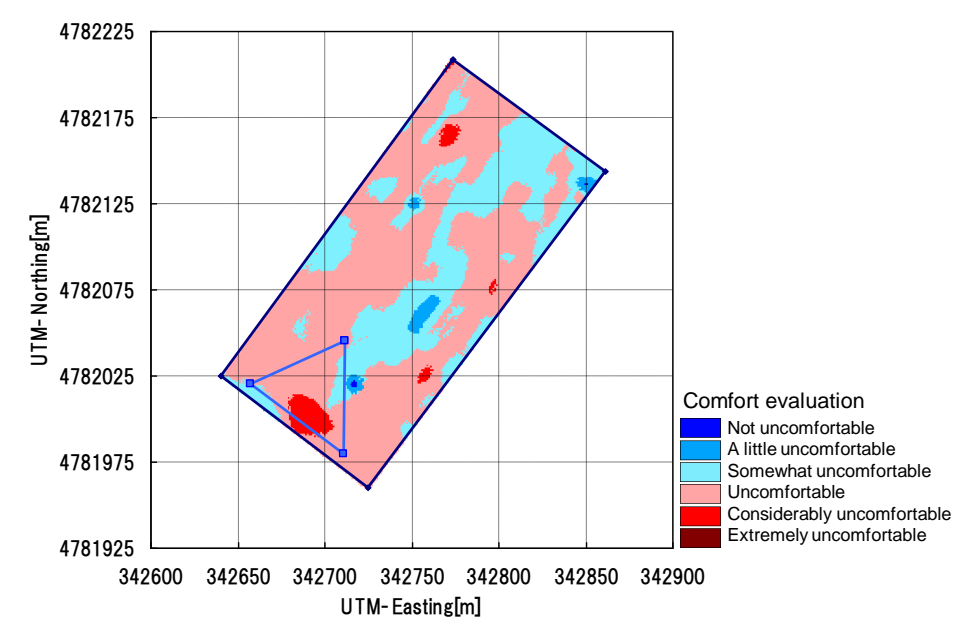

(b) Comfort evaluation using the composite vibration acceleration at $5.0 \mathrm{~Hz}$

Fig. 19 GIS map of composite vibration acceleration at the $1 / 3$ octave band centre frequency of $5.0 \mathrm{~Hz}$ and a comfort evaluation. 


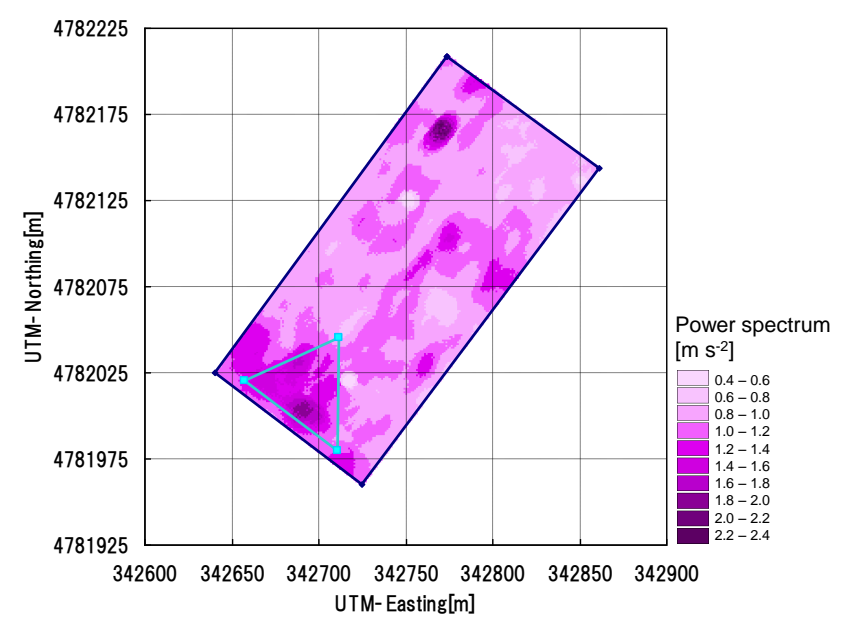

(a) Composite vibration acceleration at $8.0 \mathrm{~Hz}$.

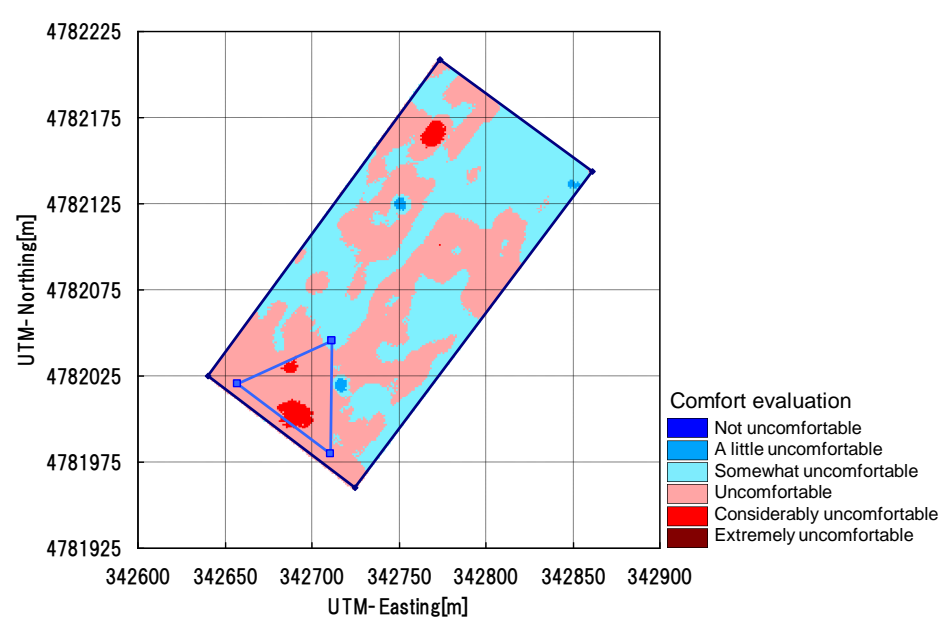

(b) Comfort evaluation using the composite vibration acceleration at $8.0 \mathrm{~Hz}$.

Fig. 20 GIS map of composite vibration acceleration at the 1/3 octave band center frequency of $8.0 \mathrm{~Hz}$ and a comfort evaluation. 